\title{
Reflection on MOOC Design in Palestine
}

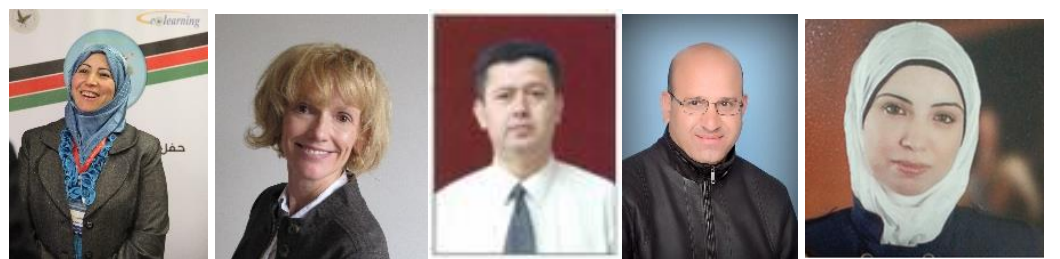

Saida Affouneh', Katherine Wimpenny'2, Ahmed Ra'fat Ghodieh'1, Loay Abu Alsaud', and Arij Abu Obaid ${ }^{1}$ ${ }^{1}$ An-Najah National University, Palestine, ${ }^{2}$ Coventry University, UK

\begin{abstract}
This paper will share Discover Palestine, an interdisciplinary Massive Online Open Course (MOOC) and the first MOOC to be created in Palestine, by the E-Learning Centre, Faculty from the Department of Geography, and Department of Tourism and Archaeology from An-Najah National University in Palestine. The paper traces the process of development of the Discover Palestine MOOC from its early inception as a cross institutional online course, to its current delivery and engagement with a global and diverse group of learners. Using a descriptive case study design and thematic analysis, the reflective experiences of four course team members involved as facilitators/designers in the design and delivery of the MOOC are shared. Three key themes, namely, "Informing pedagogies including delivery methods," "A commitment to a national cause," and "Teacher presence," are presented and contextualized with data evidence. The findings share not only the hurdles the Discover Palestine team had to navigate during the MOOC development, but more importantly, how academic collaborations promoting open education practices offer powerful tools for the reciprocal exchange of knowledge, not least in shifting mindsets, and offering opportunities for shared fields of understanding to be realized in revealing creative, cultural practices, as well as lost histories.
\end{abstract}

Keywords: Palestine, MOOC, pedagogy, OpenMed 


\section{Introduction}

In striving to preserve the cultural and religious heritage of the Palestinian people, and to increase knowledge of this heritage, the Discover Palestine initiative began in 2012 when An-Najah National University (ANNU) in Palestine, and Montclair State University in the USA, signed a cross-institutional agreement to create the Discover Palestine course to be taught at both universities. The course content explored the ancient land of Palestine, considering the geographical and ecological makeup of the land, the different types of agriculture and water installations that have been adopted by various groups over the centuries, as well as trade and other relations between groups living side-by-side and without the region. In its focus on the history of the range of groups of people who have lived in the area, the Discover Palestine course attempted to present as fair and unbiased a picture as possible, whilst also promoting learning about the art, architecture, and technology of the country through its different historical periods.

What the initiative highlighted, evidenced from the student online course evaluation, was the transformative potential of opening up teaching and learning practices through cross-institutional learning, and the way in which reciprocal respect, with regards to both Faculty and students, shifted. For example, whilst the American students were "shocked" to find the Palestinian students were not primitive but similarly technologically-advanced and progressive, the Palestinian students also expressed a new-found respect towards their American student-peers, and the difference between people and government attitudes. In short, Palestinian and American students found a common field of understanding.

In 2014, building on the success of this cross-institutional initiative, and as a result of Montclair State University moving away from Moodle as the shared course platform (and no longer offering the course), the E-Learning Center together with the Department of Geography and Department of Tourism and Archaeology at $\mathrm{ANNU}^{\mathrm{i}}$, worked together to develop the Discover Palestine course to be taught universally, transforming it into a MOOC - the first English language certified MOOC to be created in Palestine. The course was offered three times during 2015-2016 with a total of 247 participants from 45 countries registering on the course, engaging a global and diverse group of learners, and is still offered to date. This paper will reflect on the facilitator/designer learning experience of MOOC pedagogy from the first three cycles. It will also consider how the Discover Palestine MOOC has functioned as a tool for identity building.

\section{An-Najah National University}

ANNU is a vibrant hub of learning which has promoted the acquisition of modern knowledge in the fields of Medicine, Engineering, Humanities, Social Sciences, and the Natural Sciences whilst remaining committed to the transmission and preservation of Palestinian history, heritage, and culture (Affouneh \& Raba, 2017).

As a leading academic institution in the Middle East with a clear vision of progress, the university is dedicated to advancing scientific research on a global level whilst also meeting the local community's needs by participating in sustainable economic, technical, and human development. As such, ANNU is cultivating a multicultural, pluralistic outlook amongst students through a number of initiatives designed to foster cross-cultural dialogue and tolerance. As a pivotal institution in Palestine, (with 20,000 students enrolled in the university's four campuses, comprised of 13 faculties, 79 bachelors degree programs, 23 intermediate diploma programs, 52 graduate programs including 
three high diploma programs in medicine, and two $\mathrm{PhD}$ programs in chemistry and physics) the university continues to inspire its student body to realize their own potential, and to have a positive impact on the society in which they reside.

The E-Learning Center (ELC) at ANNU was founded in 2012 in order to achieve several goals which included, creating an encouraging environment of e-learning across the university faculties and academic programs; to develop both student and academics' skills in digital fluency; to spread the culture of open education practices; and to produce high-quality (blended) courses. ELC's vision has remained one of providing excellence in both learning and teaching. Whilst ANNU is focused on demonstrating excellence to engage learners and maintain its presence in the competitive market of higher education provision, of fundamental importance for the institution is to provide educational opportunities for the benefit of social learning at a local and global level through its' networked communities of learners. The ambition of ELC is therefore about capacity building; nurturing academic staff who can design and deliver effective connectivist pedagogy, and facilitate student engagement and digital competency through its course offerings, to create knowledge-producing opportunities for the betterment of society. However, whilst experienced in designing blended courses and e-learning in general, the MOOC was a new concept for the ELC team.

\section{Context and Informing Literature}

MOOCs vary immensely in their nature and content and it is outside the remit of this paper to focus on this in-depth (for a detailed discussion of the varied nature of MOOCs see McAuley, Stewart, Siemens, \& Cormier, 2010; Yuan \& Powell, 2013; Bates, 2014; Bayne \& Ross, 2014). What is evident from the research literature on MOOCs is the differing degrees of participation, reflection, collaboration, usage of multimedia, and the nature of assessment used (Terras \& Ramsay, 2015). This includes how MOOCs can offer a range of opportunities to widen access and participation in education, especially when the knowledge and capacity of both the instructors and the students are emphasized in exploring the content, while deemphasizing the teacher as the sole source of content (McAuley et al., 2010).

As identified in the review of research practices about MOOC initiatives conducted by Gašević, Kovanović, Joksimović, \& Siemens (2014), research topics which receive most attention include student attrition, engagement in learning, and assessment strategies. Less attention has focused on issues around practical guidance on course design, including "teaching presence" and how this impacts upon the learner/facilitator experience. Furthermore, despite MOOCs being a global phenomenon, the majority of research is dominated in the West, and as such, what is less clear is the experience of other countries, cultures, and economies.

What is interesting is the polarized debate within the literature about the potential of MOOCs, which on the one hand have been criticized as merely e-learning tools for the massive, with little evidence of significant impact on pedagogical practices (Selwyn, 2007; Laurillard, 2013), to the transformational practices, and ways in which MOOCs can revolutionize teaching and learning (Parr, 2015). It is evident that the massiveness of MOOCs, their accessibility, and the wide range of questions they raise, make MOOCs fertile areas for research (Bates, 2014). Though some early expectations have proven unrealistic, as Anders (2015) contends, MOOCs are a maturing technological innovation, and complementary to this, a greater diversity of MOOC practitioners and stakeholders are engaging in MOOC research within the realms of open, distance, and distributed learning. 


\section{Open Education Practice and the OpenMed Project}

OpenMed ${ }^{\mathrm{ii}}$ is an international cooperation project co-funded by the Erasmus + Capacity Building in Higher Education programme ${ }^{\text {iii }}$ of the European Union during the period October $15^{\text {th }}, 2015$ October $14^{\text {th }}, 2018$ involving five partners from Europe and nine from South-Mediterranean (S-M) Countries (Palestine, Morocco, Egypt, and Jordan). The project is focused on how universities from Palestine, Morocco, Egypt, Jordan, and other S-M countries can join in the action, as community partners, in the adoption of strategies and channels that embrace the principles of openness and reusability within the context of higher education (HE).

OpenMed fosters the role of universities as knowledge providers not only to their on-campus students but also beyond the walls of institutions. Within the project framework is the continuous need for collaboration and enhancement of sharing and networking opportunities. Open Education Practices (OEP) assume a crucial and essential role, not least due to the typical top-down governing systems of universities in S-M countries where there has been an often-timid participation of university institutions in relation to OEP.

The OpenMed project seeks to transform and support all universities across the Mediterranean region to contribute to the democratization of knowledge, focusing on a bottom-up approach to OEP. In this context, OEP is a way to give back to the universities their awareness of their role in society, not only through the use of open practices, licenses, and open education contents, but also by providing the skills and tools required for promoting active dialogue and participation in our knowledge sharing society.

As a project partner in OpenMed, colleagues from ANNU have been building relationships with HE institutions from across the two shores of the Mediterranean as well as in North Europe, and in the first phase of OpenMed the Discover Palestine MOOC was selected as a case study to provide inspiration and insight into the current practices around Open Education Resources (OER) and OEP in the S-M region, and to promote reflection and discussion about current practices and priorities for change for OpenMed (Wimpenny, Merry, Tombs, \& Villar-Onrubia, 2016 ${ }^{\text {iv }}$ )

\section{Local Context}

As a country, Palestine does not currently have a formal national policy on open education, and the Palestinian Ministry of High Education does not accredit online degrees. However, the development of a policy on open education is in progress as OpenMed has fostered a regional debate in the S-M region on what the best strategies are to embed OEP and OER in universities. This debate, which has involved HE managers, decision-makers, educators, and other members of staff as well as policy makers, revolves around the OpenMed OER Regional Agenda for the S-M, a document that, starting from an understanding of the long-term challenges and priorities which are necessary for opening up HE in the S-M countries, presents a set of strategic actions aimed at maximizing the benefits of OER and OEP to increase the access, the quality, and the equity of $\mathrm{HE}$ in the region. Concurrently, ANNU does not have a formal definition of open education but practices "openness" describing it as "offering an opportunity for learning with no boundaries."(Wimpenny et al., 2016, p. 86) The university is moving towards improved awareness of OER and OEP through OpenMed, and is developing resources such as open databases, an e-library, a university-hosted, openly available, repository of recorded lectures, journal articles, conference papers, and master's theses, accessible to learners inside and out with the university, and through MOOCs such as Discover Palestine. 
Opening up teaching and learning in Palestine through the Discover Palestine MOOC, presents an important means of achieving a just peace between Israelis and Palestinians. Through the power of online tools and open content, the story of the conflict can be heard from both sides. Arguably, Israelis have been able to deliver their story, mainly to Europe and North America, more efficiently than the Palestinians. The Discover Palestine MOOC was viewed as offering an efficient means of helping present the Palestinian story to thousands of people around the world, and to provide a platform for discussion and debate. This may contribute to the global efforts to solve the conflict peacefully, and to enable the Palestinian people to have their rights restored.

\section{MOOC Course Design}

The pedagogical considerations inherent in effective MOOC design deserve attention. Arguably, MOOCs have tended to be technologically-driven not least as their provision was enabled by the interconnected nature of the Internet (Terras \& Ramsey, 2015). However, in order that longer-term educational benefits can be realized, MOOCs must become pedagogically-driven and informed by the rapidly developing knowledge base of e-learning theory and practice (Fischer, 2014).

As such, there is a key role in capacity building for teachers/facilitators in the future success of effective MOOC-based learning (Bayne \& Ross, 2014). The challenge for Faculty is in how their role and presence is defined, and if they are to be viewed more as a curator/facilitator than a teacher. As Allen and Seaman (2013) contend it takes more time and effort for a Faculty member to teach an online course than to teach a corresponding face-to-face course, and with that come other considerations such as semester schedules, and how Faculty consider managing the interaction with a global set of leaners across time zones. What is clear is that building online courses is not about mirroring existing face-to-face frameworks, which do not work in the MOOC format. Yet, Faculty are often faced with teaching on a range of courses and struggle to manage competing modes of pedagogical delivery.

\section{Reflections From Staff About the Complexities and Challenges Inherent in Delivering MOOC Pedagogy}

In focusing on ways to address the demands on course delivery across face-to-face, blended, and onlineonly course offerings, Faculty and e-learning colleagues at ANNU, as course team members, were prompted to question what can be delivered effectively through a MOOC in a way that benefits their oncampus students, as well as the value in engaging the hundreds of other global learners, including those who do not have the privilege of attending HE. Drawing on descriptive case study methodology, (Simons, 2009), used to develop a detailed account of the subject of study, question prompts were initiated and developed by the second author, and lead researcher of the OpenMed Compendium. As the OpenMed project is focusing on capacity building in order that academics from universities in the S-M adopt strategies that embrace the principles of openness, it felt appropriate that the Discover Palestine team shared their facilitator/designer learning experience of MOOC pedagogy. Four staff including the Director of ELC (first author), the Head of the Geography Department (third author), a Lecturer from the Department of Tourism and Archaeology (fourth author), and a Research Teaching Assistant (fifth author), shared their experiences with the second author, who then used thematic analysis (Braun \& Clarke, 2006) to analyze the reflective responses. The analysis focused on how the data sets revealed the course teams' perspectives about the learning experience of designing, delivering, and facilitating the MOOC. The analytic process progressed from description, where the reflective data were organized to show patterns in content, and summarized to interpretation, where themes were developed, illustrating the significance of the patterns and their broader meanings and implications. 
This required an iterative process of reading, re-reading, preliminary coding, and generation of themes and their subthemes. Themes were defined and contextualized with data evidence and shared with the course team for member checking. The following section goes on to present the key findings under three main themes, namely informing pedagogies including delivery methods, a commitment to a national cause, and, teacher presence.

\section{Informing Pedagogies Including Delivery Methods}

Whilst the course team had previous experience of delivering blended and e-learning courses, this was a first-time experience to design and deliver the Discover Palestine MOOC and the initial pedagogical approach was geared towards a content transmission mode of learning, including delivery methods such as setting weekly readings and structured activities around tasks and projects.

It was evident that "learning by doing" was key as well as having a set of outline aims for the MOOC that helped to provide the course design features, which included, the need for content to be accessible in English - as a focus was to reach out to new and diverse learners - and, for the content to be engaging, multimodal, and of high quality.

Designing a MOOC was my first time, but it was not my first experience in blended courses and e-learning in general, I designed several blended courses before and have supervised many courses, and have conducted many training sessions for hundreds of teachers at our university. However, the MOOC was a new concept for me and my colleagues, so we learned by doing and we learned through an online course for designing a MOOC and through our reading online about MOOCs, and through the research papers published. It was a very challenging task, but learning by doing was our methodology. (Director of ELC, ANNU)

The course team researched about Learning Management Systems (LMS) for MOOCs to find that Moodle itself could be used as the MOOC platform, and as ANNU uses Moodle as its LMS, the Discover Palestine course was hosted there.

It was also recognized that "the amount and quality of knowledge and information required for a MOOC is much more that of traditional teaching methods" (Research and Teaching Assistant) and, how there was preparatory work required to enrich the course with different types of resources: audio, video, and text. Developing teaching resources required capacity building and efficient team work. They assigned specific tasks amongst one another; Faculty staff as content providers, the ELC staff as pedagogy experts who helped transfer content into the online resources, with support from Learning Technologists' know-how. They took time to think about what content would work best, and with which visual and audio materials.

It was evident that the team experienced uncertainty in the mapping of the course content and the learning resources. There was concern about how to ensure a baseline for quality and a questioning of whether they were "doing it right?" and indeed how could this be confirmed, and by whom? Here, the team drew on the support of an external evaluator to evaluate and comment on the content. There was also ANNU's International Department, who helped with proof reading the English translations including the video footage.

In terms of the content mapping, several factors were under debate in terms of how much content to include without creating too much workload difficulties, and in responding then to learner needs and 
translation issues. Of more significance, was the sensitivity of the topic relating to the Palestinian-Israeli conflict, and the historical mapping of content to help promote all that could be shared about Palestine, including writing content in an objective balanced way; "especially as we live in a very tense political situation, and it was difficult to think about ways to write that all people could accept" (Research and Teaching Assistant, ANNU).

Due to the conflict within the region over the past decades, the state of historical and archaeological research has been insufficiently developed and the course team felt under pressure to resolve this problem with confidence. Considering these circumstances, it was necessary to identify this transparently as an area of concern, and to lay out the evidence as fairly and accurately as possible. For example, in terms of the tensions between land rights and the naming of occupied territories, the team choose one of the several possible ways of referring to areas of the land, or the people within it, explaining their choices, e.g., "Palestinian" and "Canaanites," etc. From a chronological perspective, the course covered a broad period of time extending from the Late Bronze Age to the earliest Islamic periods. In order to add depth to the course, therefore, it was necessary to focus on some periods more closely than others, and learners were encouraged to complement their learning by researching and exploring some of the more superficially covered periods.

\section{A Commitment to a National Cause}

No significant incentives initially existed for the Discover Palestine team to get the MOOC project off the ground from an institutional perspective, (although ANNU teaching staff are now offered points to support promotional opportunities within the institution, including a decreased teaching load). Rather, the initial driving force was through a genuine commitment of the staff in this being their professional role coupled with a strong sense of "national duty." As the Director of ELC shared:

In my experience studying my $\mathrm{PhD}$ in the UK, I had met many people who did not know anything about Palestine and that made feel sorry and unhappy and this motivated me to introduce my country in an academic way, and thanks to the Internet this is possible.

And further, "We believe in the human dimension of life, and people need to know each other - wherever they live"(Lecturer, Department of Tourism and Archaeology).

Indeed, the course team committed extra hours on top of their day-to-day roles and responsibilities to take the online training course about MOOC design and how to develop the multimedia resources.

A significant amount of effort was involved for not only delegating, planning, designing, and creating the course content and associated resources, but thereafter in promoting the course and experiencing the "delivery time," including the engagement of learners and facilitation of the online interaction.

MOOCs are time consuming but offer an opportunity to be part of the open international community. Designing and delivering a MOOC is an interesting journey, full of challenges and excitement. To be sure, many worthy experiments will fail or have a different outcome than desired. But if failed experiments were an obstacle to doing world-changing research, we academics would probably choose a different job. (Head of Geography Department, ANNU) 
It was also expressed that "whilst international students, and staff were able to discuss issues online and [t]his technology makes people from different countries and backgrounds closer and encourages them to cooperate on their understandings of Palestine" (Research and Teaching Assistant), managing the differences in time created a barrier for conducting any "live learning sessions." This felt challenging for the course team, who, on the whole, were more used to facilitating synchronized learning.

\section{Teacher Presence}

The Discover Palestine MOOC set out to serve a "massive" student population and was "open" in the sense that the ANNU course creators did not charge learners a fee for participating in the experience, although no course credit was offered to online students either.

In managing the course delivery, the team experienced a particularly steep learning curve in being responsive, managing the larger numbers of students, and the methods required for engagement and course facilitation.

We urged the participants to express their views freely, especially when dealing with geopolitical issues. We also expected learners to read about the set subjects, view the available videos, and discuss their content with each other and with the tutor as well. (Head of Geography Department, ANNU)

A time-consuming task was in managing intercultural dialogue around content considering international relations, especially as the team were working with a diverse community of learners (and in English).

We have learned that it is not easy to understand different peoples' perspectives. We faced the challenge of having participants from different backgrounds and we wanted to be sure we met their needs, and understood their meanings and perspectives.... We have learned that we should have an international expert to support us. (Lecturer, Department of Tourism and Archaeology)

The need for extra support was with specific regard to being able to discuss the accuracy of resources shared, and the challenge to find Palestinian and international resources to feed into the discussion. The team acknowledged that it would be valuable to draw on more strategic support:

I learnt that the university should coordinate its work with the Ministry of Education; the Ministry of Foreign Affairs, Consulates and Embassies in Palestine to support us in projects such as this, in addition to creating new stakeholders inside and outside Palestine. (Head of Geography Department, ANNU)

However, what came as more of a surprise for the Discover Palestine team was that whilst the main thrust of the course was about sharing new narratives of Palestine, to educate and inform a wide and more internationally diverse audience about Palestinian history, culture, architect, art, and culture, many Palestinians in exile and also local people from Palestine participated. The course was announced through the university website (https://elc.najah.edu/node/304), via Facebook, and also through the university broadcasting channel. In addition, the MOOC can be found through searching on the Internet, and on the mooclist (https://www.mooc-list.com/). Thus, Palestinian people heard about, and saw the importance and relevance of taking the course too. 
We appreciate just how many people need to know more about Palestine since they have not had the chance to visit Palestine as their parents or grandparents left after the Nakba in 1948 to different places in the world. The surprise and tension for us at the same time was that two people from Israel also registered for this course. A further surprise was that one participant came to volunteer at ANNU after finishing the course. (Lecturer, Department of Tourism and Archaeology)

As a consequence of the above, the Discover Palestine course is now offered as a free blended university course, in English, for all honors students each semester at ANNU, in order to increase national awareness.

The following figures show the learner distribution by subject area, academic level and gender for the first three cycles of the course. Table 1 then presents the distribution of learners by country, illustrating the geographical reach of the Discover Palestine MOOC.

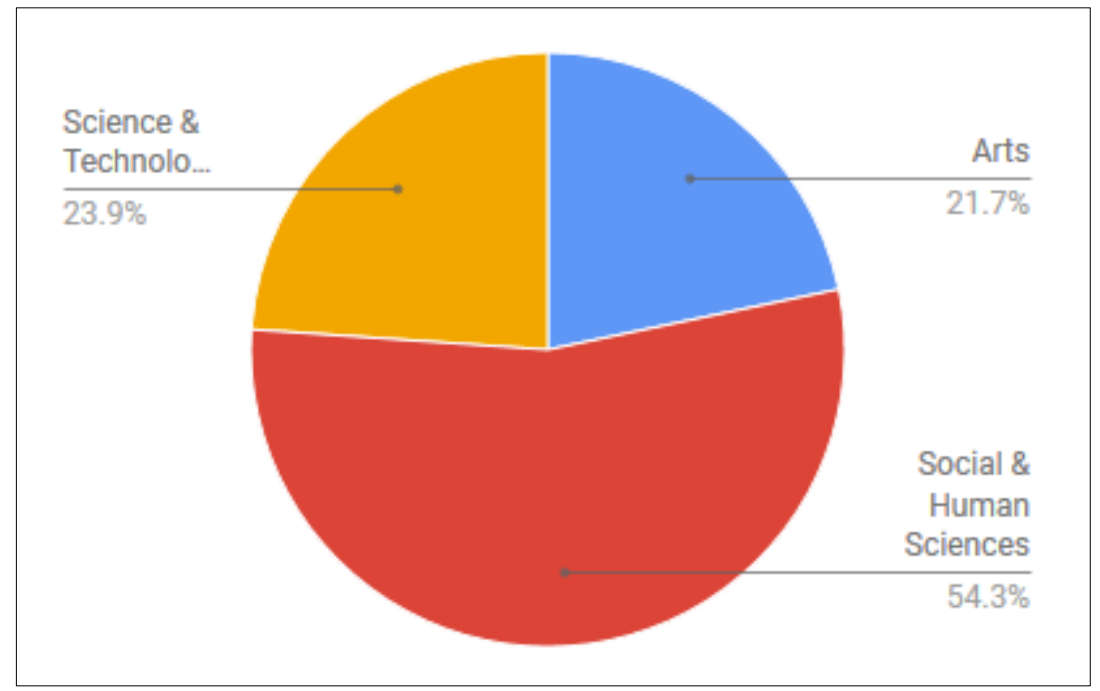

Figure 1. Learner distribution by subject area.

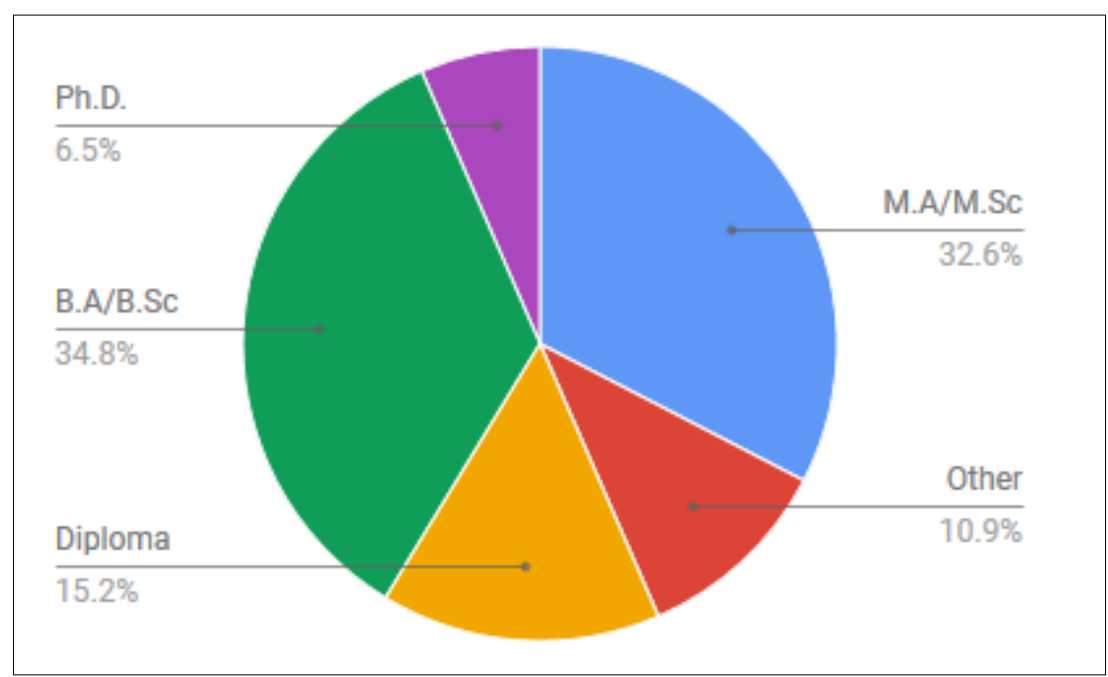

Figure 2. Learner distribution by academic level. 


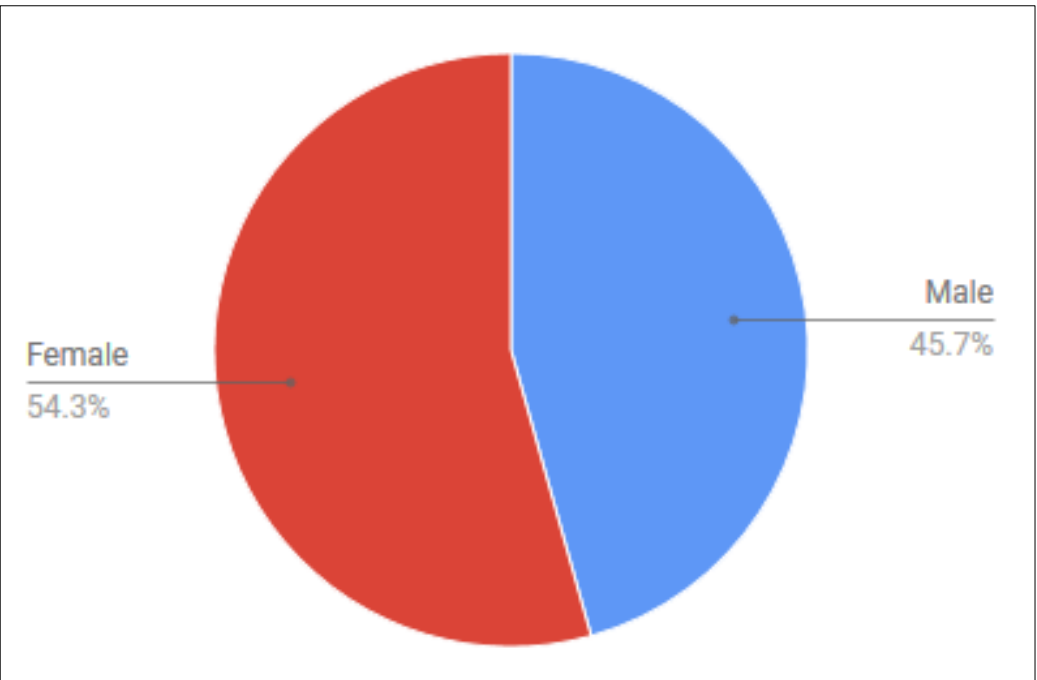

Figure 3. Learner distribution by gender.

Table 1

Learner Distribution by Country 2015-2016

\begin{tabular}{|c|c|c|c|c|c|c|c|}
\hline Country & Palestine & United States & $\begin{array}{l}\text { United } \\
\text { Kingdom }\end{array}$ & Spain & India & Italy & France \\
\hline No. & 76 & 30 & 26 & 12 & 11 & 10 & 7 \\
\hline Country & Malaysia & Netherlands & Canada & Morocco & Sweden & Australia & Germany \\
\hline No. & 6 & 6 & 4 & 4 & 4 & 3 & 3 \\
\hline Country & Hungary & Indonesia & Jordan & Mexico & Argentina & Brazil & Colombia \\
\hline No. & 3 & 3 & 3 & 3 & 2 & 2 & 2 \\
\hline Country & Israel & Norway & UAE & Afghanistan & Bulgaria & Chile & China \\
\hline No. & 2 & 2 & 2 & 1 & 1 & 1 & 1 \\
\hline Country & Croatia & Greece & Iceland & Ireland & Mauritius & Pakistan & Philippines \\
\hline No. & 1 & 1 & 1 & 1 & 1 & 1 & 1 \\
\hline Country & Portugal & Romania & Serbia & Slovenia & Somalia & Sudan & Switzerland \\
\hline No. & 1 & 1 & 1 & 1 & 1 & 1 & 1 \\
\hline Country & Thailand & Vietnam & Yemen & & & & \\
\hline No. & 1 & 1 & 1 & & & & \\
\hline
\end{tabular}




\section{Discussion}

\section{Generative Learning}

In designing their first MOOC, this case study has illustrated the shift in understanding about the informing pedagogy and ways to better integrate the insights of social-constructivist pedagogical theories (Poplar, 2014). What became evident for the Discover Palestine team was how, through the open discussion of learning experiences, an important opportunity was made possible for communities of learners, both local and global, to take part in the sharing of historical facts and cultural practices. Indeed, many of MOOC students reported that the course was better than anything available at the "brick-and-mortar campuses" to which they had access.

The MOOC learning space prompted the storytelling and generation of new insights about Palestinian culture and history, which will continue to be available on the course website as well as through individual learners' own blogs and social media accounts. Downes (2012) discusses this type of knowledge-growth and the power of networks of connected and connective knowledge over time. However, only limited research has explored the impact of MOOCs and what they can contribute to historical research generation (Gallagher \& Wallace, 2016). It was interesting to note how the Discover Palestine MOOC thus offered an unanticipated generative repository for oral history sharing, bringing a number of benefits for adding content to less detailed archival knowledge, as well as serving as an opportunity to invest in new and rich ways for Palestine to tell "its" story.

In terms of resources, the course team still question how much content learners can / should try to digest considering all the periods of history and archaeology in Palestine which they would wish to promote, and how otherwise the course can be reduced to that which is essential. However, what the team now appreciate more fully is the power of constructivist and connectivist approaches to facilitate emergent, self-organized patterns of collaborative learning (Downes, 2012), wherein groups of people learn with, and from one another, and where this can lead in extending and expanding upon ways of knowing:

Of course but there was no resource, the people on the course became the best resources, the open resources through the Internet were also very important resources. (Director of ELC, ANNU)

In addition, each subsequent offering of the Discover Palestine MOOC, emerges from, and is built on the previous. In this way, the course content itself is shaped through the development of evidence informed by connectivist learning principles of diversity, openness, and interactivity (Milligan, Littlejohn, \& Margaryan, 2013) and without the necessary mediation of a centralized authority (Anders, 2015).

It is evident that a number of key roles and partnerships can help support ventures such as these not least for ANNU in supporting the initial commitment and willingness of academic staff to take risks and pursue new modes of teaching and learning for the betterment of society. Further, it is important to add how the ANNU Strategic Management Team as stakeholders were keen to support the Discover Palestine MOOC, and give the staff their approval. This now includes:

- The senior university team who have supported the course and kept abreast of issues; 
- The Office of International Affairs in An-Najah National University; and

- The Palestinian Ministry of Foreign Affairs, The Ministry of Education, and the importance of national recognition considering the content and the aim of the MOOC.

Further, OpenMed has continued to help validate the ANNU venture with the Discover Palestine MOOC having been reviewed and included in the Compendium of good practice ${ }^{v}$, which as a consequence also served to empower the staff. Having such support has given the team the confidence to continue and also the ability to critique and reflect upon their practices.

I think through the OpenMed project I am exposed to more understanding and experiences which now empower me and I am more confident, especially after including our experience in Discover Palestine as a case study in the Compendium, and how it was evaluated externally. But we are still learning. (Research and Teaching Assistant)

And further,

Now we are working on designing and delivering another two MOOCs, one is Genetics and Society in Arabic, and the other is Conservative Energy in English. I will be the team leader again and use my previous experience from Discover Palestine and learn from the derived lessons to make the two new ones better. Also, my involvement in the OpenMed project continues to provide me with up-to-date knowledge and new skills, and has empowered me in my facilitator role and consideration of use of resources in open learning for our MOOCS. I believe that these new courses will be much better due to this. (Director of ELC, ANNU)

What is of note is how the team now have the confidence to promote MOOCs for Arabic learners as well as MOOCs for international learning communities and have developed the course twice since the first delivery, mainly in decreasing the "required" reading materials and instead adding in more content and links through the generative learning resources. They have also decreased the number of assignments. Further, the educational practices of connectivist pedagogy, with emphasis on socially-intensive and interactive learning experiences, have supported the team in reviewing their role less as instructor, and more as interlocutor and facilitator.

\section{Conclusions}

ANNU already had extensive experience in blended e-learning courses. However, living under Israeli occupation for more than 50 years, was an incentive for the E-Learning Center along with colleagues from the Department of Geography and Department of Tourism and Archaeology, to build on a crossinstitutional course, and design a MOOC. The Discover Palestine MOOC is promoting new narratives for the country, to a wide and diverse number of people around the world, embracing Palestine's history, archaeology, geography, arts, cultural heritage, and geopolitical developments of Palestine's cause.

In addition, Discover Palestine has brought together a learning community which transcends nationality, religion, colour, background, and level of education. It has opened up a space and place for all learners to contribute in open discussion freely, and to access resources and information in a range of rich media formats, including text, photographs, pictures, videos, and lectures. Further, the content 
is developed through the community of learners who have shared additional resources and contributed readings, adding to the open education resources.

The team have experienced a number of challenges in terms of managing diverse learner needs and interpreting global perspectives in as fair and evidenced way as possible. Nonetheless, the Discover Palestine MOOC has offered the course team opportunity to reflect upon how online communities help foster learning, and how social networking can help both online and in-person community building. Whilst a steep learning curve, it has not put the team off, and another two MOOCs are currently under design. 


\section{References}

Allen, I. E., \& Seaman, J. (2013). Changing course: Ten years of tracking online education in the United States. The Online Learning Consortium. Retrieved from https://www.onlinelearningsurvey.com/reports/changingcourse.pdf

Affouneh, S., \& Raba, A. (2017). An emerging model of e-learning in Palestine: The case of An-Najah National University. Creative Education, 8, 189-201. doi: 10.4236/ce.2017.82016

Anders, A. (2015). Theories and applications of massive online open courses (MOOCs): The case for hybrid design. International Review of Research in Open and Distributed Learning, 16(6). Retrieved from http://www.irrodl.org/index.php/irrodl/article/view/2185/35

Bates, T. (2014). MOOCs: Getting to know you better. Distance Education, 35(2), 145-14. doi:10.1080/01587919.2014.926803

Bayne, S., \& Ross, J. (2014). The pedagogy of the massive open online course: The UK view. Recuperado el: The Higher Education Academy, 3o. Retrieved from https://www.heacademy.ac.uk/system/files/hea edinburgh mooc web 240314 1.pdf

Braun V., \& Clarke V. (2006) Using thematic analysis in psychology. Qualitative Research in Psychology, 3(2) 77-101. doi: 10.1191/1478088706qpo63oa

Downes, S. (2012). Connectivism and connective knowledge: Essays on meaning and learning networks. National Research Council Canada. Retrieved from http://www.downes.ca/files/books/Connective Knowledge-19May2012.pdf

Gallagher, S., \& Wallace, C. (2016). A far cry from school history: massive online open courses as a generative source for historical research. International Review of Research in Open and Distributed Learning, 17(5). Retrieved from http://www.irrodl.org/index.php/irrodl/article/view/2673/3882

Gašević, D., Kovanović, V., Joksimović, S., \& Siemens, G. (2014). Where is research on massive open online courses headed? A data analysis of the MOOC research initiative. The International Review of Research in Open and Distributed Learning, 5. Retrieved from http://www.irrodl.org/index.php/irrodl/article/view/1954/3099

Fischer, G. (2014). Beyond hype and underestimation: identifying research challenges for the future of MOOCs. Distance Education, 35, 2, 1-10. doi:10.1080/01587919.2014.920752

Laurillard, D. (2013). Rethinking university teaching: A conversational framework for the effective use of learning technologies. London, Routledge

McAuley, A., Stewart, B., Siemens, G., \& Cormier, D. (2010). The MOOC model for digital practice. elearnspace.org. Retrieved from http://www.elearnspace.org/Articles/MOOC_Final.pdf 
Milligan, C., Littlejohn, A., \& Margaryan, A. (2013). Patterns of engagement in connectivist MOOCs. MERLOT Journal of Online Learning and Teaching, 9(2), 149-159. Retrieved from http://jolt.merlot.org/volgno2/milligan 0613.htm

Parr, C. (2015). MOOCS: Fluctuating rates in online investment. Times Higher Education. Retrieved from https://www.timeshighereducation.com/news/moocs-fluctuating-rates-in-onlineinvestment/2019816.article

Poplar, D. (2014). MOOC evolution and one poetry MOOC's hybrid approach. Educause Review Online. Retrieved from http://www.educause.edu/ero/article/mooc-evolution-and-onepoetry-mooc's-hybrid-approach/

Selwyn, N. (2007). The use of computer technology in university teaching and learning: a critical perspective. Journal of Computer Assisted Learning, 23 (2), 83-94. doi:10.1111/j.13652729.2006.00204.x

Simons, H. (2009). Case study research in practice. London: Sage.

Terras, M. M., \& Ramsay, J. (2015). Massive open online courses (MOOCs): Insights and challenges from a psychological perspective. British Journal of Educational Technology, 46(3) 472-487. doi:10.1111/bjet.12274

Wimpenny, K., Merry, S.K., Tombs, G. \& Villar-Onrubia, D. (Eds) (2016). OpenMed: Opening up Education in South Mediterranean Countries: A Compendium of Case Studies and Interviews with Experts about Open Education Practices and Resources. OpenMed, ISBN 978-1-84600-0.

Yuan, L., \& Powell, S. (2013). MOOCS and disruptive innovation: Implications for higher education. Open Education Europa. Retrieved from http://publications.cetis.org.uk/wpcontent/uploads/2013/03/MOOCs-and-Open-Education.pdf

iThree of the team had graduated from European universities with PhDs, and had some experience of project work with international communities, both in face to face and online contact.

iiMore information on the OpenMed Project can be found at: http://www.OpenMedproject.eu

iiihttp://eacea.ec.europa.eu/erasmus-plus/actions/key-action-2-cooperation-for-innovation-and-exchange-good-practices

iv https://openmedproject.eu/results/compendium/. 